\title{
Single-lap dissimilar joints between AA6061/SiC/20p and hybrid thermoplastic composites: In-plane impact strength and elastic energy during quasi-static indentation process
}

\author{
Nahit Öztoprak ${ }^{1}$, Çınar Emine Yeni ${ }^{1}$, \\ ${ }^{1}$ Department of Mechanical Engineering, Dokuz Eylul University, Izmir, Turkey, 35390
}

\begin{abstract}
.
Direct (adhesive-free) adhesion techniques have been drawing more attention to join dissimilar materials in recent years. The goal of this research is to gain a better understanding on the mechanical properties of directly-bonded dissimilar joints between hybrid polypropylene (PP) composites and SiCp/AA6061. Two different hybrid composites reinforced with aramid fabric are considered in the study. One layer of aramid fabric is placed to the middle of the $2 \mathrm{~mm}$ thick thermoplastic composite (TPC) panels (20 wt.\% and $40 \mathrm{wt} . \%$ long glass fiber reinforced), separately with a stacking sequence of [TPC-2mm/fabric/TPC-2mm]. Afterwards, single-lap joints (SLJs) are manufactured through a hot pressing process under a specific force and temperature. Quasi-static indentation (QSI) experiments are performed at the overlap region on the TPC to evaluate the absorbed elastic energy during penetration. Moreover, in-plane impact behavior of the joints is studied. The results show that the hybrid adherend with a higher fiber amount provides a superior resistance force in the QSI. Besides, there is a lower elastic energy-displacement slope in the SLJs comprise of hybrid structure with a fewer fiber ratio. It has also been observed that the increasing fiber percent in the PP composite has a positive effect on the in-plane Charpy impact strength.
\end{abstract}

Keywords: lap-bonded joint, metal-matrix composite, hybrid composite, aramid, mechanical properties

\section{Introduction}

Due to their superior properties and widespread use, silicon carbide (SiC) reinforced aluminum matrix composites (Al-MMCs) (Kumar et al., 2020), (Knowles et al., 2014), (Chatterjee et al., 2016) may need to be joined with various types of composites for specific applications. Hybrid thermoplastic composites (TPCs) are widely used to achieve enhanced physical and mechanical properties compared to composites formed with a single type of reinforcing material (Gogoi et al., 2019), 
(Kalajahi et al., 2020). Aramid fibers exhibit outstanding characteristics of high abrasion resistance (Ayrilmis et al., 2014), good impact and thermal safety (Wang et al., 2018) that distinguish them from other reinforcements. It is well known that aramid fiber/polypropylene (PP) composites have shown high toughness (GonzalezChi et al., 2017). However, the relatively expensive nature of aramid fibers raises the need to reduce their amount of fabric layers without compromising the desired properties of final composite (Carrillo et al., 2012). To this end, two different hybrid composites are developed in the study, with one layer of aramid fabric between long glass fiber-reinforced PP composites of the same thickness.

Joints with prospective damage initiation points are considered as the weakest link in the lightweight structures (Peng et al., 2020). As one of the simplest links to fabricate, single-lap joints (SLJs) are commonly preferred for the engineering applications likely to be subject to light-loads (Reis et al., 2012). Accordingly, evaluation of the mechanical properties of joints should be carefully examined under in-plane impact and after the possible penetrations occur in the bonding region. Several studies have been conducted on the mechanical properties of single-lap dissimilar joints. Baffari et al. (Baffari et al., 2018) evaluate the mechanical resistance of the joints between AA6082-T6 and self-reinforced PP fabricated by a novel Friction Stir Welding (FSW) based approach. Various hole geometries are investigated through shear tests. Furthermore, a numerical model is used to examine the effects of parameters on the process mechanics. Their results indicate that the introduction of a chamfer at the base of the hole drilled in the aluminum sheets enhances the joint resistance. The high-efficiency resistance welding is performed to manufacture hybrid joints of the titanium (Ti) alloy plate and the glass fabric reinforced polyetherimide (GF/PEI) laminate by the researchers (Xiong et al., 2020). The influence of welding time on lap shear strength is also studied. To summarize findings of the study, coating flame-grown carbon nanotube (CNT) layer of Ti alloy can improve the interlaminar strength. Welding time plays an important role on the lap shear strength because it first increases at a certain period of time and then decreases. Ramaswamy et al. (Ramaswamy et al., 2020) present a novel interlocked hybrid method to join aluminum (Al) with carbon- fiber thermoplastic composite. Quasi-static and transient dynamic tests are then performed on the fabricated joints. Interlocking adhesive joints (IAJs) show a better performance in terms of lap-shear strength and work to failure by comparison with baseline adhesive joints (BAJs). Different types of weld inserts are integrated during manufacturing of glass fiberreinforced PP sheets in the compression mold without fiber damage by the scientists (Troschitz et al., 2020). Afterwards, the TPC is welded to steel sheets through the process parameters based upon the numeric welding simulation. Their experimental results reveal that the head design of weld inserts has a significant contribution to the load-carrying capacity of the SLJs. Although dissimilar joints of thermoplastic composite with metallic materials have been extensively investigated, there is still no research on the characterization of the SLJs between SiCp/AA6061 and hybrid PP composites. Furthermore, it is important to understand how dissimilar joints are affected from mechanical loading of overlap region. Therefore, joint behaviors under QSI and in-plane impact are examined in this research. 


\section{$7^{\text {th }}$ International Conference On}

Modern Approaches in SCIENCE, TECHNOLOGY \& ENGINEERING

\section{8-20 June, 2021 \\ Brussels, Belgium}

\section{Experimental details}

\subsection{Materials}

In this study, commercially available (nuh Kompozit Inc.) homopolypropylene composite granules with $20 \mathrm{wt} . \%$ and $40 \mathrm{wt} . \%$ long glass fibers are used for the fabrication of TPC panels. The average length of fibers is about $12 \mathrm{~mm}$. The typical properties of the PP composites extracted from datasheet of the supplier are summarized in Table 1 (nuh Kompozit, 2021). Plain weave (uniform) aramid fabric $\left(0.6 \mathrm{~mm}\right.$ thick) with an areal density of about $500 \mathrm{~g} / \mathrm{m}^{2}$ is utilized for the fiber hybridization of the TPCs. Figure 1 exhibits the composite granules fabricated by pultrusion method and the aramid fabric appearance. The commercial Al-MMC (AMC620XF, Materion, Hampshire, England) consisting of 6061-T1 Al alloy matrix and $20 \% \mathrm{SiC}(0.7 \mu \mathrm{m})$ particulate reinforcement is chosen as the metallic adherend. Table 2 lists the physical properties of the MMC (Materion Brush Inc., 2020).

Table 1: Properties of the thermoplastic composites by the supplier

\begin{tabular}{lll}
\hline Properties & Duramax & Duramax \\
& LFT20-PP & LFT40-PP \\
\hline Glass fiber percent $(\%)$ & 20 & 40 \\
Density $\left(\mathrm{g} / \mathrm{cm}^{3}\right)$ & 1.03 & 1.20 \\
Tensile strength $(\mathrm{MPa})$ & 92 & 119 \\
Flexural strength $(\mathrm{MPa})$ & 125 & 190 \\
Izod impact, unnotched $\left(\mathrm{kJ} / \mathrm{m}^{2}\right)$ & 30 & 37.5 \\
\hline
\end{tabular}

Figure 1: Photos of the composite granules and aramid fabric
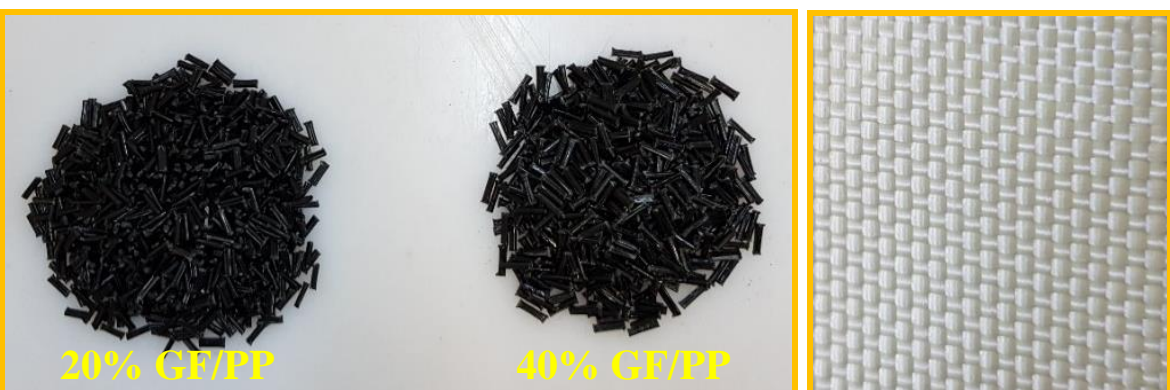

Table 2: Physical properties of the MMC

\begin{tabular}{ccccccc}
\hline $\begin{array}{c}\text { Density } \\
\left(\mathrm{g} / \mathrm{cm}^{3}\right)\end{array}$ & $\begin{array}{c}\text { Elastic } \\
\text { Modulus } \\
(\mathrm{GPa})\end{array}$ & $\begin{array}{c}\text { Specific } \\
\text { Stiffness } \\
\left(\mathrm{GPa} / \mathrm{g} / \mathrm{cm}^{3}\right)\end{array}$ & $\begin{array}{c}\text { Poisson's } \\
\text { Ratio }\end{array}$ & $\begin{array}{c}\text { Thermal } \\
\text { Conductivity } \\
@ 25^{\circ} \mathrm{C} \\
\left(\mathrm{W} / \mathrm{m}^{\circ} \mathrm{K}\right)\end{array}$ & $\begin{array}{c}\text { Solidus } \\
\left({ }^{\circ} \mathrm{C}\right)\end{array}$ & $\begin{array}{c}\text { Specific } \\
\text { Heat } \\
\text { Capacity } \\
\left(\mathrm{J} / \mathrm{g} /{ }^{\circ} \mathrm{C}\right)\end{array}$ \\
\hline 2.8 & 103 & 36 & 0.3 & 150 & 570 & 0.85 \\
\hline
\end{tabular}

\subsection{Surface treatment of aramid fabrics}


It has been reported that the surface modification of aramid fibers (AFs) provides advantages on the adhesion and compatibility between polymer matrix and AFs (Ahmad et al., 2006), (Maity et al., 2007), (Chen et al., 2013). To this end, a chemical surface modification is performed to enhance fiber-matrix adhesion. Firstly, sulfuric acid $\left(\mathrm{H}_{2} \mathrm{SO}_{4}\right)$ is applied at ambient temperature for $120 \mathrm{~s}$ to the high performance aramid fabrics cleaned with acetone. The fabrics are washed with running water and then dried. After this preliminary treatment, the AFs are put into a sodium hydroxide $(\mathrm{NaOH})$ aqueous solution with $10 \%$ volumetric concentration for $30 \mathrm{~min}$ at a room temperature $\left(23 \pm 2{ }^{\circ} \mathrm{C}\right)$ followed by rinsing through running water. Finally, the fabrics are dried in an oven at $50^{\circ} \mathrm{C}$ for $30 \mathrm{~min}$. Chemical treatment process of the AFs is demonstrated in Figure 2.

Figure 2: Surface treatment procedure of AFs

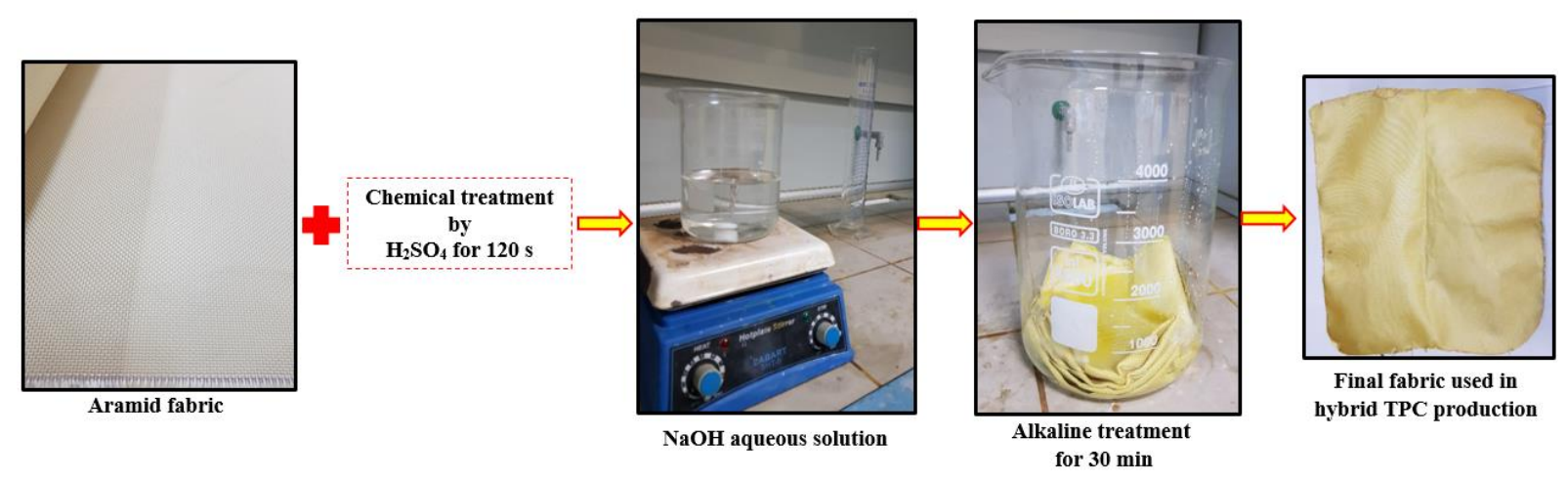

\subsection{Fabrication of hybrid composites}

Panels of long glass fiber reinforced-TPCs are prepared through a metallic mold with $2 \mathrm{~mm}$ thickness before the fabrication of hybrid composites. Four plates with two different fiber amounts (two for each fiber ratio), $20 \mathrm{wt} . \%$ and $40 \mathrm{wt} . \%$, are prepared. The composite granules are homogeneously positioned into the mold $(350 \times 350 \times 2$ $\mathrm{mm}^{3}$ ) and then the mold is placed inside a hot press machine, which is kept at the constant force of $100 \mathrm{kN}$ and constant temperature of $210{ }^{\circ} \mathrm{C}$ for 50 minutes, followed by a slow cooling for about 24 hours at a constant force to ambient temperature. Herein, it is important to insert polytetrafluoroethylene (PTFE) films between the granules and the hot metal plates. After the TPC panels are fabricated, the novel hybrid TPCs with a thickness of $4 \mathrm{~mm}$ are obtained by placing the chemically treated aramid fabric between two composites of the same thickness. Thus, two different hybrid composites are developed with one layer of aramid fabric between the PP composites. Hybrid manufacture is performed with a constant force of $100 \mathrm{kN}$ at 210 ${ }^{\circ} \mathrm{C}$ for 50 minutes as in the preparation of the TPC panels. Figure 3 shows the stacking schematic of the TPCs manufactured within the scope of the research. 
Figure 3: Schematic illustration of fabricated hybrid TPCs

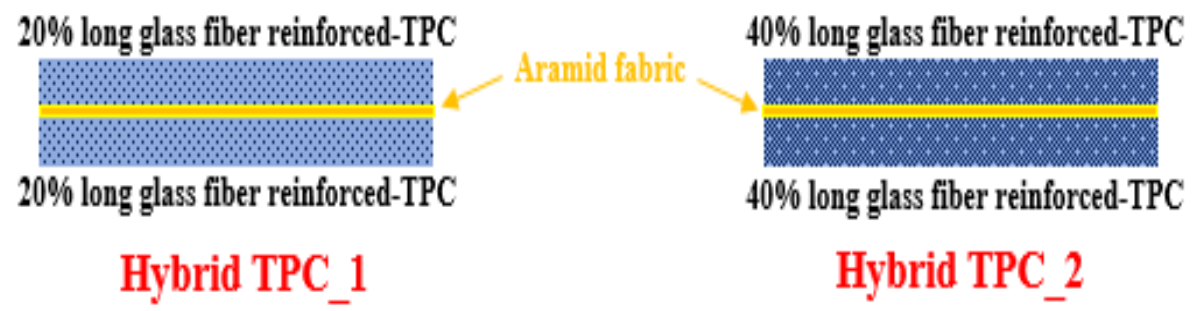

\subsection{Single-lap joint preparation}

Surface treatments are carried out on the metallic sheets before the joint manufacture. The first treatment comprises of cleaning with acetone followed by a drying process by compressed air. The second procedure consists of sanding smoothly with \#400 grits sandpaper. Afterwards, the MMC plates are rinsed with running water and finally dried in an oven. The last procedure comprises of the chemical treatments. The plates are submerged into an aqueous solution of $11 \%$ hydrochloric acid $(\mathrm{HCl})$ and $89 \%$ distilled water for 30 minutes, followed by a rinsing stage with running water. The AA6061/SiC/20p-T1 sheets are then treated with a solution of sodium hydroxide $(\mathrm{NaOH})$ at $10 \%$ by weight for 2 minutes, followed by a rinsing stage again with distilled water and finally dried through a drier. The last chemical process is performed at $70{ }^{\circ} \mathrm{C}$. After the surface modifications, hot-pressing technique is performed for the preparation of SLJs. The MMC adherends with $300 \times 100 \times 3.8$ $\mathrm{mm}^{3}$ (length $\times$ width $\times$ thickness) dimensions are positioned in the mold of $8 \mathrm{~mm}$ height, the upper and lower surfaces of which are covered with PTFE films. The PTFE coated special spacers with the same thickness of the metallic adherends are then put in position to cover the remaining space. In order to obtain SLJs, the TPC adherends with $4 \mathrm{~mm}$ thickness are placed on the MMC adherends considering the overlapping length of $25.4 \mathrm{~mm}$. Finally, the hot plate press is operated for the novel single-lap dissimilar joints at $210^{\circ} \mathrm{C}$ for 50 minutes with $100 \mathrm{kN}$ force, followed by a slow cooling for 24 hours at a constant force. In this way, the hybrid TPCs and AA6061/SiC/20p are directly bonded without using any kind of adhesives. The crosssection geometry of lap joints is schematically depicted in Figure 4.

Figure 4: Schematic illustration and dimensions of single-lap dissimilar joints (in $\mathrm{mm}$ ) 

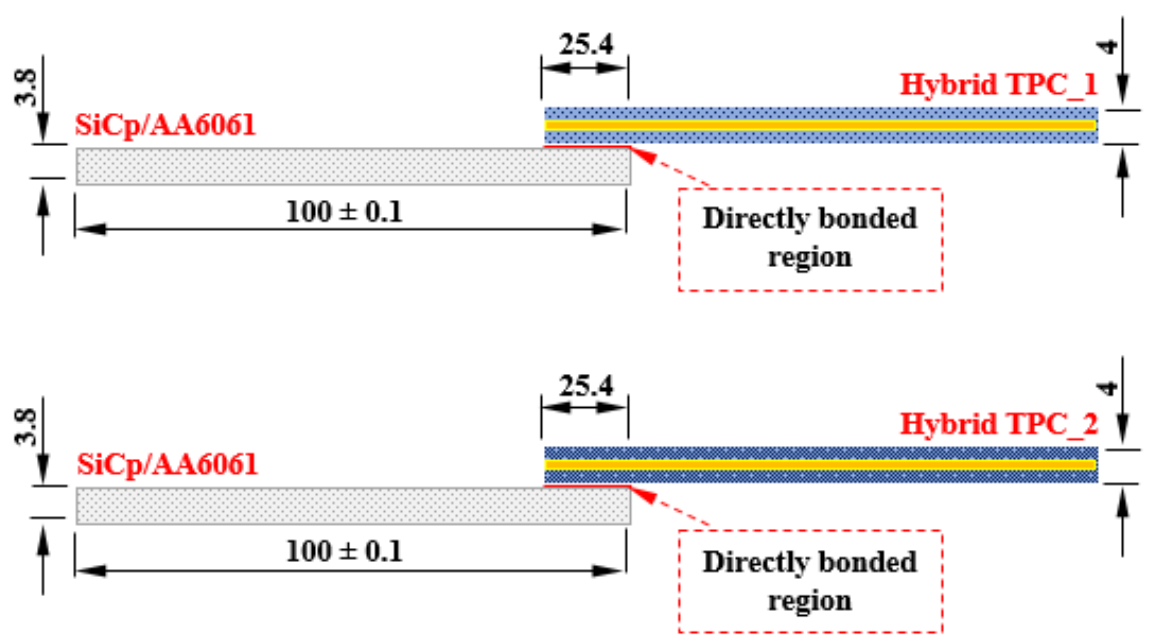

\subsection{Quasi-static indentation (QSI) and impact tests}

QSI tests are performed on the hybrid TPCs of the dissimilar joints using a Shimadzu AG-X $(100 \mathrm{kN})$ universal testing machine and test apparatus in the Mechanical Engineering Laboratory of Dokuz Eylul University to evaluate the absorbed elastic energy of SLJs during QSI. The tests are carried out under displacement controlled condition considering the punch displacement of $4 \mathrm{~mm}$ at the constant rate of 1.25 $\mathrm{mm} / \mathrm{min}$ in accordance with ASTM D6264 (ASTM International, 2017). The QSI experiments are conducted within the elastic behavior of the composites. In this way, energy absorption response of the SLJs have been studied. The cylindrical indenter was steel with a diameter of $12.7 \mathrm{~mm}$. Three samples are tested for each condition and the tests are terminated after reaching the desired displacement. The amount of energy absorbed is estimated by integrating the area under the resistance load-displacement curves. Charpy pendulum tests are also carried out in order to determine the in-plane impact strength of the dissimilar joints. Three samples are tested at ambient temperature. A pendulum Charpy test device is used to investigate the in-plane impact response of the SLJs. All the impact tests are performed with a mass of pendulum of $18.75 \mathrm{~kg}$ and a swing length of $825 \mathrm{~mm}$. All the specimens are simply supported by anvils with a $41 \mathrm{~mm}$ support span.

\section{Results and discussions}

\subsection{QSI response}

Indentation force-punch displacement curves are recorded during the QSI tests. A comparison of the findings of two different SLJs is demonstrated in Figure 5. The curves represent the average response of three samples tested. As can be seen in the figure, there is an explicit difference between the joint behaviors in the elastic region. An enhanced resistance load is obtained through the application of the indenter to the hybrid TPC_2 with higher fiber amount. In other words, the hybrid TPC_2 adherend of the dissimilar joints provides a better perforation resistance against the flat tip compared to that of the hybrid TPC_1. The calculated average forces at the punch 


\section{$7^{\text {th }}$ International Conference On}

Modern Approaches in SCIENCE,

TECHNOLOGY \& ENGINEERING

\section{8-20 June, 2021}

Brussels, Belgium

displacement of $4 \mathrm{~mm}$ are found to be $686.98 \mathrm{~N}$ and $786.56 \mathrm{~N}$ in the QSI through the hybrid TPC_1 and hybrid TPC_2, respectively. This highlights the importance of the fiber amount in the loaded adherend on the perforation resistance.

The area under the resistance force-punch displacement curves is used to estimate the quasi-static energy absorption in the tests. The total energy absorbed by the composites is the sum of the elastic energy, energy in the damage region and frictional energy. However, only elastic energy in the course of QSI is considered within this work. The absorbed energy for each lap joint is determined by trapezoidal integration in an Excel program and the mean of the findings is used for comparison. Figure 6 shows the absorbed energy-displacement curves estimated from the tests. It is evident from Figure 6 that the SLJs with hybrid TPC_2 absorb more elastic energy by comparison with the responses at the punch displacement of $4 \mathrm{~mm}$. From the figure, it can be inferred that a greater energy-displacement slope is obtained in the samples of hybrid TPC_2. The amount of elastic energy absorbed in the SLJs with hybrid TPC_1 and hybrid TPC_2 are approximately $1.43 \mathrm{~J}$ and $2.41 \mathrm{~J}$, respectively. The results indicate that the SLJs under the punch displacement of $4 \mathrm{~mm}$ absorb 1.68 times more energy by changing the penetrated adherend from hybrid TPC_1 to hybrid TPC_2.

Figure 5: Comparison of the resistance force responses in elastic region

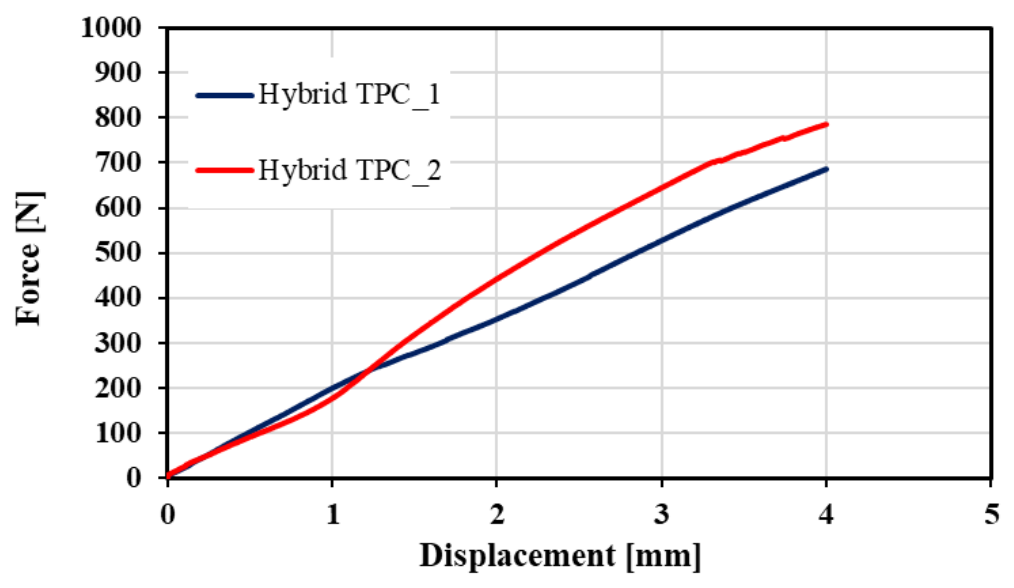

Figure 6: Comparison of the energy responses at $4 \mathrm{~mm}$ 


\section{$7^{\text {th }}$ International Conference On}

Modern Approaches in SCIENCE,

TECHNOLOGY \& ENGINEERING

18-20 June, 2021

Brussels, Belgium

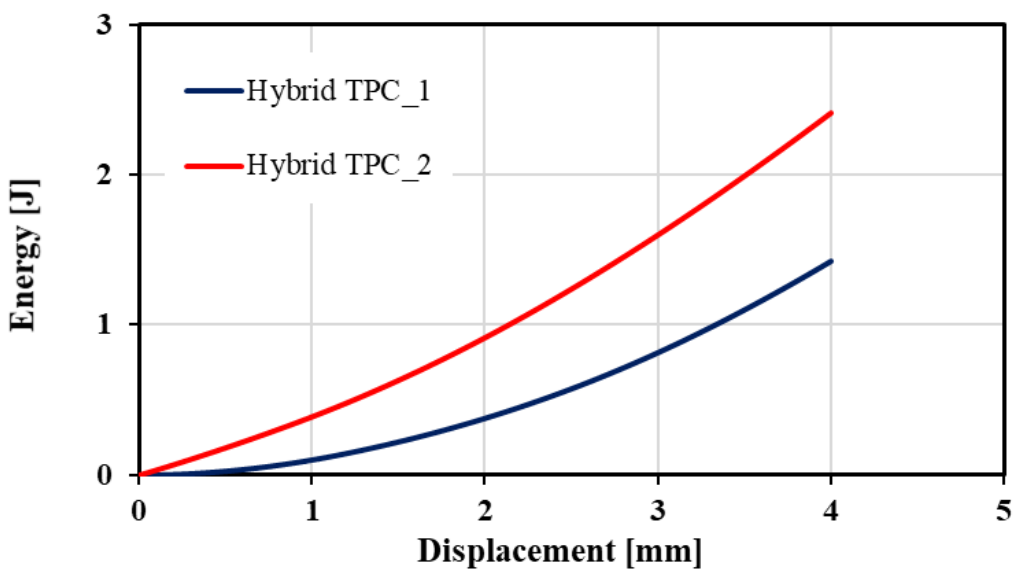

\subsection{In-plane Charpy impact behavior}

The values of Charpy impact strength under in-plane strike for the SLJs that comprise of different hybrid adherends with various amounts of E-glass fiber are presented in Figure 7. The results demonstrate the average of three samples. An enhancement in the absorbed energy with increasing content of E-glass fiber in hybrid TPC is observed. SLJs with hybrid TPC_2 have almost $11.4 \%$ more impact strength than those of the dissimilar joints with hybrid TPC_1. The samples that contain hybrid TPC_2 show an increase in the impact strength from 897.88 to $1000.21 \mathrm{~kJ} / \mathrm{m}^{2}$. This finding clearly demonstrates that the increasing fiber percent in the hybrid composite has a positive effect on the in-plane impact strength of SLJs. Considering fracture surfaces after impact tests, transverse fracture of the hybrid TPC and interface debonding between the aramid fabric and PP matrix can be assumed as the main failure mechanisms. In hybrid composites, separation is seen between the fabric and the bottom TPC panel. It is noteworthy that there is no interface debonding between metal and polymer. Figure 8 depicts the fracture positions of the samples.

Figure 7: Comparison of the impact test results 


\section{$7^{\text {th }}$ International Conference On}

Modern Approaches in SCIENCE, TECHNOLOGY \& ENGINEERING

18-20 June, 2021

Brussels, Belgium

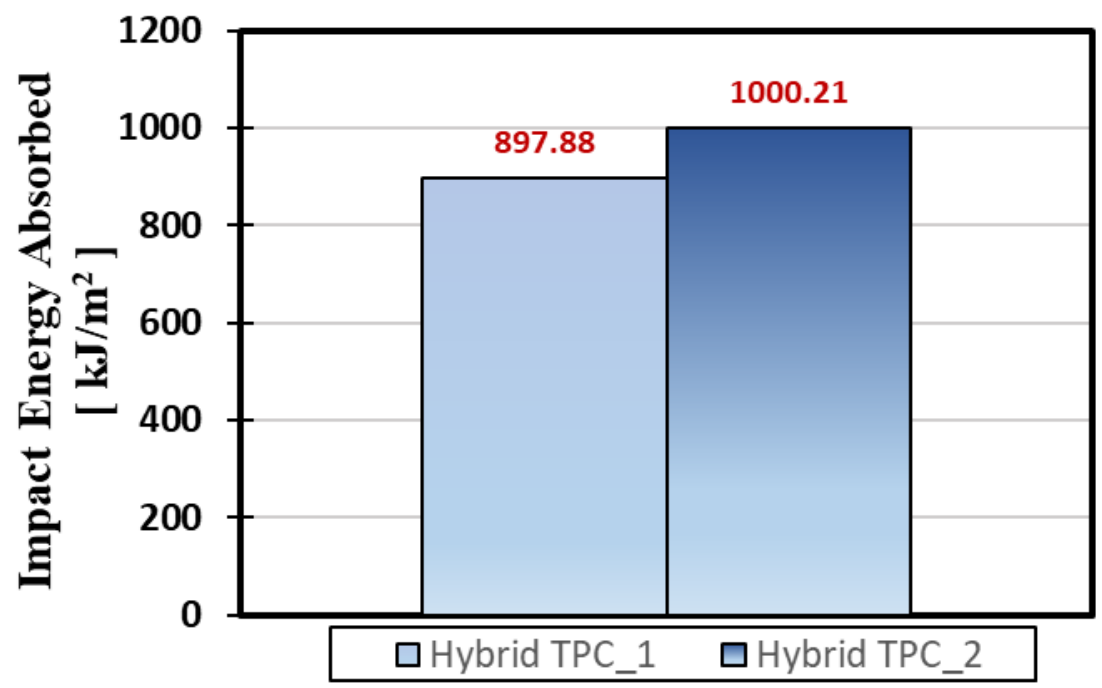

Figure 8: Failure mechanism of the SLJs through in-plane impact

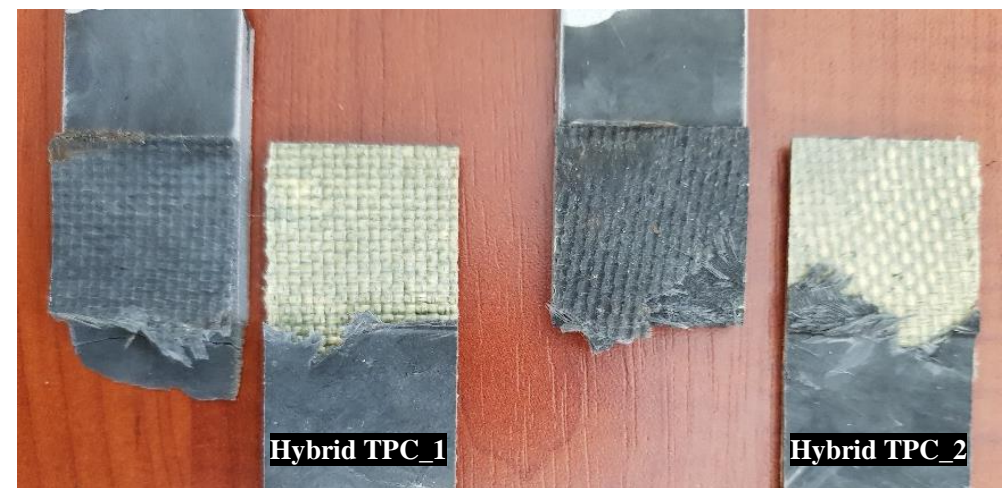

\section{Concluding remarks}

An alternative joining technique through hot-pressing is introduced to obtain metal/polymer SLJs. Two different hybrid composites reinforced with aramid fabric are manufactured in the research. The hybrid TPCs are directly bonded to $\mathrm{SiCp} / \mathrm{AA} 6061$ without using any kind of adhesives or additional materials. In-plane impact behavior and elastic response under QSI of the SLJs are evaluated. The main findings are summarized as follows:

a) The use of hybrid TPC_2 as the adherend in the SLJs increases the resistance force in the elastic region of QSI.

b) When the dissipated energy at $4 \mathrm{~mm}$ is compared, SLJs of hybrid TPC_2 results in a greater energy-displacement slope. 
c) The Charpy impact strength of SLJs fabricated by hybrid TPC_2 is enhanced compared to the samples with hybrid TPC_1.

d) According to the fracture surface of the SLJs subsequent to impact, fabric/matrix debonding in the hybrid TPCs is the dominant failure mechanism.

\section{References}

Kumar, C. R., Malarvannan, R. R. R. and JaiGanesh, V. (2020). "Role of SiC on Mechanical, Tribological and Thermal Expansion Characteristics of $\mathrm{B}_{4} \mathrm{C} / \mathrm{Talc}$ Reinforced Al-6061 Hybrid Composite," Silicon, vol. 12, pp. 1491-1500.

Knowles, A. J., Jiang, X., Galano, M. and Audebert, F. (2014). "Microstructure and mechanical properties of $6061 \mathrm{Al}$ alloy based composites with $\mathrm{SiC}$ nanoparticles," Journal of Alloys and Compounds, vol. 615, pp. S401-S405.

Chatterjee, S., Sur, S. G., Bandyopadhyay, S. and Basumallick, A. (2016). "Effect of microstructure and residual stresses on nano-tribological and tensile properties of $\mathrm{Al}_{2} \mathrm{O}_{3}$ - and SiC-reinforced 6061-Al metal matrix," Journal of Composite Materials, vol. 50, pp. 2687-2698.

Gogoi, R., Manik, G. and Arun, B. (2019). "High specific strength hybrid polypropylene composites using carbon fibre and hollow glass microspheres: Development, characterization and comparison with empirical models," Composites Part B: Engineering, vol. 173, 106875.

Kalajahi, P. F., Shahbazi, A., Shelesh-Nezhad, K. and Arsalani N. (2020). "The effects of aramid short fiber and $\mathrm{CaCO}_{3}$ nanoparticles inclusions on the elastic, damping, and thermal behavior of polypropylene composite," Journal of Thermoplastic Composite Materials, vol. 33, pp. 1707-1720.

Ayrilmis, N., Kwon, J. H. and Han, T. H. (2014). "Improving bending and tensile properties of lignocellulosic filled polypropylene composite panels using aramid fabric," Fibers and Polymers, vol. 15, pp. 2410-2415.

Wang, J., Chen, P., Lu, C., Yu, Q., Li W. and Ren R. (2018). "Improvement of aramid fiber III reinforced bismaleimide composite interfacial adhesion by oxygen plasma treatment," Composite Interfaces, vol. 25, pp. 771-783.

Gonzalez-Chi, P.I. et al. (2017). "Influence of aramid fiber treatment and carbon nanotubes on the interfacial strength of polypropylene hierarchical composites," Composites Part B: Engineering, vol. 122, pp. 16-22.

Carrillo, J. G., Gamboa, R. A., Flores-Johnson, E. A. and Gonzalez-Chi, P. I. (2012). "Ballistic performance of thermoplastic composite laminates made from aramid woven fabric and polypropylene matrix," Polymer Testing, vol. 31, pp. 512-519.

Peng, X., Liu, S., Huang, Y. and Sang L. (2020). "Investigation of joining of continuous glass fibre reinforced polypropylene laminates via fusion bonding and hotmelt adhesive film," International Journal of Adhesion and Adhesives, vol. 100, 102615.

Reis, P. N. B., Ferreira, J. M. and Richardson, M. O. W. (2012). "Effect of the Surface Preparation on PP Reinforced Glass Fiber Adhesive Lap Joints Strength," Journal of Thermoplastic Composite Materials, vol. 25, pp. 3-13. 


\section{$7^{\text {th }}$ International Conference On}

Modern Approaches in SCIENCE,

TECHNOLOGY \& ENGINEERING

\section{8-20 June, 2021 \\ Brussels, Belgium}

Baffari, D., Buffa, G., Campanella, D., Lo Valvo, E. and Fratini L. (2018). "Experimental and numerical investigation on a new FSW based metal to composite joining technique," Journal of Manufacturing Processes, vol. 34, pp. 758-764.

Xiong, X. et al. (2020). "Enhanced resistance-welding hybrid joints of titanium alloy/thermoplastic composites using a carbon-nanotube lamina," Diamond and Related Materials, vol. 101, 107611.

Ramaswamy, K., O'Higgins, R. M., Corbett, M. C., McCarthy, M. A. and McCarthy, C. T. (2020). "Quasi-static and dynamic performance of novel interlocked hybrid metal-composite joints," Composite Structures, vol. 253, 112769.

Troschitz, J., Vorderbrüggen, J., Kupfer, R., Gude, M. and Meschut, G. (2020). "Joining of Thermoplastic Composites with Metals Using Resistance Element Welding," Applied Sciences, vol. 10, 7251.

http://nuhkompozit.com.tr/en/(accessed 5 March 2021).

https://materion.com/-/media/files/aerospace-metal-composites/supremex/supremex-

620xf-data-

sheet.pdf?la=en\&hash=B674C2448C7999831E51555A8E6D35A9D347A5D1.

(accessed 5 March 2021).

Ahmad, I., Wong, P. Y. and Abdullah, I. (2006). "Effects of fiber composition and graft-copoly(ethylene/maleic anhydride) on thermoplastic natural rubber composites reinforced by aramid fiber," Polymer Composites, vol. 27, pp. 395-401.

Maity, J. et al. (2007). "Fluorinated aramid fiber reinforced polypropylene composites and their characterization," Polymer Composites, vol. 28, pp. 462-469.

Chen, X-S. et al. (2013). "Improving the flame retardancy of the polypropylene/aramid fiber composites by the introduction of decabromodiphenyl ethane and antimony trioxide," Journal of Applied Polymer Science, vol. 127, pp. 1446-1453.

ASTM International. (2017). D6264/D6264M-17 Standard Test Method for Measuring the Damage Resistance of a Fiber-Reinforced Polymer-Matrix Composite to a Concentrated Quasi-Static Indentation Force. Retrieved from https://doi.org/10.1520/D6264_D6264M-17 